Article

\title{
BFE Model-Business, Family and Environment-As Subsystems of the Family-Owned Business in Mexico City Metropolitan Area
}

\author{
Omar de la Cruz Vicente ${ }^{1, *}$, Verónica Itzel López Castro ${ }^{2}$ (D), Leovardo Mata Mata ${ }^{2}$ and \\ Fernando Tomé Bermejo ${ }^{1}$ \\ 1 Business Department, Universidad Antonio de Nebrija, 28015 Madrid, España; ftome@nebrija.es \\ 2 Business School, Universidad Anahuac, Mexico City 52786, Mexico; itzel.lopez@anahuac.mx (V.I.L.C.); \\ leovardo.mata@anahuac.mx (L.M.M.) \\ * Correspondence: ocruz@nebrija.es
}

Received: 22 April 2019; Accepted: 14 May 2019; Published: 16 May 2019

\begin{abstract}
This work proposes a model starting from the Three-Circle Model, based on the reality of the small and medium-sized family business sector in the Mexico City Metropolitan Area. The present paper proposes a new model that was built based on the Three Circle Model, but it is based on the reality of the Small and Medium Mexican family business sector. The model does not include the Ownership Subsystem, but it includes the Environment Subsystem, a subsystem that has a vital influence on the life and performance of an organization of that size. These three subsystems intersect in common elements such as culture, economy or company vision, triggering the success or failure of the company itself. The methodology used was a mixed methodology, with both qualitative and quantitative elements. First, the Delphi method was used on a scale that was applied to 25 owners of Small and Medium Enterprises and then, to make an additional confirmation, hypothesis testing, factorial analysis and the technique of structural equations were used. It was seen that the ownership subsystem has a lower weight than the business, environment and family subsystems, is the least relevant.
\end{abstract}

Keywords: business administration; three-Circle Model; small and medium-sized business

\section{Introduction}

The study of the Family Business (FB) is recent, unconsolidated and has developed notably in recent years, but for the most part research in this area focuses on large-sized businesses [1]. The reason for this is that much of the business literature comes from the United States, where family businesses are the majority and represent $90 \%$ of the business population [2]. In addition, the literature focuses mostly on case studies or some special issues [3].

The study of the FB formally dates back to 1975 with the publication of "Beyond Survival: A Guide for the Business Owner and His Family" by Leon Danco PhD. Subsequently, two more facts transformed the research of this type of company: "the publication of the special issue of Organizational Dynamics magazine in 1979 and the launch of the specialty magazine Family Business Review in 1986" [2]. The consolidation of the topic began in the 1990s and more researchers emerged with the creation of the Center of FBs at Cleveland [3].

A relevant literature review conducted by Benavides, Guzmán \& Quintana [1], through journals indexed in the Social Science Citation Index, from 1961 to 2008, found that the first article that focuses on the topic dates from 1961. This article was prepared by Trown [4] with the title "Executive succession in small companies" and was published in Administrative Science Quarterly. The same research 
indicated that from 1961 to 1982, only seven articles on the subject were located, in comparison with the year 2008, in which 60 articles were located. This article highlights the non-linear growth in the literature of the topic.

The research on the family business has also gone through an evolution. At the beginning, there were classified studies within the sociology category. Then, relevant research also began to be classified in the Small and Medium Enterprises (SMEs) category. And then, in the management category, and little by little, entering inside other categories. In fact, the literature on the subject is not particularly voluminous and has focused on very specific topics of interest, such as succession, management, governance, family dynamic, finance and business growth; while there are some forgotten topics, especially complex ones. All of this make it so difficult to research this type of organization, combining business topics with psychological issues and family dynamics issues (such as culture, marketing, taxes or corporate social responsibility). It is also important to note that the type of publications on which you can find this type of contents has been changing over the years, meaning that there are specialized magazines dedicated especially to this type of organization. Regarding the contributions in the subject per country, the most active are: the United States, Canada, the United Kingdom and Spain, with the important note that most of the literature comes from universities and the most productive is the University of Alberta, located in Canada [4].

One of the reasons why that there isn't much literature on certain topics could be that the FB changes ownership very quickly (as becoming professionalized is left in the hands of the family) [5]. Studying the two concepts (business and family) is complex because they are completely different systems, relationships created in the business and the family [6], and the situations that come up go beyond business logic. On the other side of the FB complexities, one reason to research this topic is that large global companies have better rankings than those that are family-owned [7].

This document tries to fill the gap of research in Latin America, because the FBs are the biggest group of companies, but also, most of them are SMEs, not big companies. The research of family SMEs in Mexico, therefore, can be very important, from the 5,144,056 business units that already exist, $99.8 \%$ are SMEs, according to 2010 National Census of the National Institute of Statistics and Geography of Mexico (INEGI). In addition, the State of Mexico and Mexico City (Metropolitan Area) occupy the second and first places in terms of number of units. They also occupy the first two places in terms of the number of people that they employ of the total employed staff. Added to that, according to INEGI, the Mexican SMEs generate 52\% of the Gross Domestic Product (GDP) and provide 72\% of all formal jobs. Therefore, it is evident that the Mexico's economy rests on the SMEs' shoulders, most of them being FBs. Many of them were developed to work on family tasks, but they grew to give employability and support to the family members [8].

The purpose of this paper is to propose a model that represents the system of Mexican FBs that are at the same time SMEs, based on existing theories on this type of businesses. The proposed model was based on the well-known "Three Circle Model" proposed by Tagiuri and Davis [9], which integrates three subsystems: business, family and ownership. In the adaptation of the proposed model, the ownership subsystem was replaced by the environment subsystem. The main hypothesis that this paper seeks to prove is that the existing systemic models of the FB do not represent the entire reality of Mexican SMEs. FBs not only deal with the duality of business and family subsystems, but they also deal with effects from the environment subsystem.

The existence of another possible subsystem, particularly the ownership subsystem, could not be relevant in Mexican FBs that are SMEs at the same time, because the ownership is usually focused on members of the family, and, normally, those outside the family do not have participation in the business as shareholders.

\section{Characteristics and Challenges of the Family Business}

There are many definitions of what a FB is, going through those that only consider ownership as part of the definition [6], to those that even consider the roles of each person in the company [10]. 
There are also, definitions that consider the possibility of inheriting control of the company and those that combine several of the previous concepts [11,12]. Unlike other types of organizations, part of the personnel in these types of businesses also form part of the family, or if there is an open vacancy open, the possible recruiting sources to fill it should be its members [13]. Charbel et al. [11] also indicates that the center variables that are described in the most definitions are: "ownership, family involvement, family control and the intention of transferring the business to future generations as key components".

One of the main characteristics of a family business is commitment. In the FB, commitment originates with the founder, who puts in place a series of distinctive beliefs and behaviors about the business, these beliefs prevail until the entrance of the next generation, who can endorse or not endorse this same commitment [14]. Le Breton-Miller and Miller [15] emphasize that the commitment and identification of the family with the firm decreases according to the generation in which the family business is currently at. The founder's commitment is usually very strong, the second generation presents a commitment that is still strong but contains a certain degree of conflict and the third or cousin consortium has a much lower degree of commitment. In many cases, an important point that reflects the commitment is the use of the family name as a brand, this also contributes to the identity of the family itself [11].

Another characteristic of the FBs is their different way of assigning roles to family members within the organization. Home roles can be passed on to the company; and, as a consequence, these relationships set off various types of conflicts. The lack of structure and clarity in roles and functions often translates into serious psychological problems, which can end up triggering huge conflicts [16] and generating a mix of the family's ownership with the company's ownership [17].

A highlight of this kind of company is that the family that founds the company is not only the owner of the company but also, in this union of family and business subsystems, it is able to impose their values, culture, rules, politics, roles, etc. In the FBs that have good management, the employees end up feeling like part of the family. The contractual relationship is not only laboral but also sentimental [16]. Tápies proposes that these family principles that give the family and the business its identity are what guarantee its continuity over time. In fact, this continuity can be observed in the succession and survival of the organization [7]. As a result of this, decision-making becomes quicker and generates less bureaucratic organizations.

In this mix of roles and culture, it is easy to imagine the different kind of conflicts that can appear. In contrast with big organizations, in small ones, a mix of roles, culture and ownership are common [17]. Balancing working relationships and personal ones is one of the main challenges for the FBs. Just as in big companies there is Corporate Governance, there should be Family Government for the FBs [18].

In these organizations, the successors' knowledge about the business can be given from a very early age. The successors need to join the business so that they understand what the company does, that they can understand that common good must be placed before the individual ego, and so that they can value the work that was done by their predecessors [19]. Leach suggests that when the succession process draws near, the founder faces different possibilities: designate a family member, name an interim president, designate a professional manager, sell the business, sell a part of the business, split the business into parts for its complete sale, or do nothing [20].

About financial performance, empirical evidence demonstrates good performance of FBs when compared to non-family ones. According to research done on FBs, Cheng [21] concluded that the FBs are more profitable than businesses in which the shareholders are more dispersed. Unlike non-FBs, the FBs base their success not only on profitability but also on family harmony [22]. The majority of the FBs that don't reach the third generation often have intra-family conflicts, survival of the business over the long-term depends on how these conflicts are managed [12].

Regarding to the company's management, there have been recurring subjects in literature about the FBs. The establishment of policies and definition of strategies to improve management (especially if we are talking about SMEs) are subjects for research that should include not only analysis of the business's externalities but also its internalities in order to avoid informal management of the organization [23]. 
The family dynamic has a series of problems too, which tend to be transferred to the business. All these problems, sooner or later, end up being problems for the business itself [12]. To avoid this problem, each company will have its own configuration of governing committees, which will be most appropriate for the business's needs [24]

Regarding management and control, there is another important widely studied aspect, the existing agency problem between managers and shareholders proposed by Berle and Means. To avoid this kind of problem, it is crucial to separate the management decisions and the control decisions [25].

Two other important challenges that family businesses face are innovation and Corporate Social Responsibility (CSR). Regarding Innovation, there are discrepancies between FBs and non-FBs, in the FBs each founder could have different horizons of risk or plans, so, the innovation level depends on that differences [26].

Regarding CSR, there are two positions in relation to the behavior that the FB has about its management. The first states that families have preference over the business and, as a result they don't carry out their social responsibilities. The second, more complete and more evolved, maintains, that the FBs can be associated with support for the community and employees [27].

Other important challenges faced by this type of companies are: to base its success not only on profitability but on family harmony [22]; to privilege the satisfaction of family members to keep them motivated [28]; the succession process or even that the founder doesn't want to retire and finds excuses to avoid this [29] and the complicated management of human resources for the different ways to make decisions [13].

In Latin America, according to Trevinyo-Rodríguez [19], FBs usually lack a suitable management system, which results in the large confusion as to the true role of the family with the company and its management. To improve management, giving structure to the business, it is necessary to establish the governing committees that will allow for a much more orderly operation. In addition, Latin American companies deal with other types of problems, such as nepotism or even assigning jobs to unqualified people or discrimination against women in the family.

\section{Systemic Models for the Family Business}

Different theories of systems applied to the FBs have been developed. There are two types of theories to explain how the FBs work: orthodox theories and heterodox theories. The systemic models from Tagiuri \& Davis, Gersick et. al. or Carlock and Ward are orthodox theories [30], most of them are centered in the all system and are described in conceptual models, rather than being empirically based. Most of the heterodox theories are centered in some issues for the FBs using the succession theory or the agency theory [30].

An excellent approach to the reality of the family business and its definition is found in the well-known "Three-Circle Model" [9]. In this model, the FB is explained from a systemic perspective. The Family Business System in turn is made up of three subsystems: Family, Ownership and Business. Before this approach, only the study of two subsystems had been considered: the family and the business. In the Three-Circle Model, each subsystem is represented by a circle that overlaps at some point with the other subsystems. Thus, each person that forms part of the system could form part of one or various subsystems at the same time. To a large extent, this relationship explains the complexity of the relationships that may exist in the FB. This is because the priorities of each member of the system change depending on their placement within it, as can be seen in Figure 1.

A notable evolution of the previous model is the one known as the "Three-Dimensional Developmental Model" [6]. Respecting the three subsystems mentioned in Tagiuri and Davis, it delves more deeply into the different stages that make up each subsystem over time and the changes. This model considers that businesses are inevitably affected by the aging of those forming part of the business. 


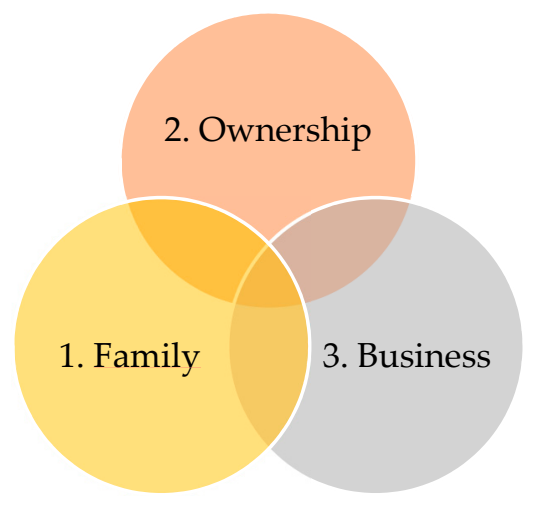

Figure 1. Three-Circle Model. Source: Tagiuri \& Davis (1996).

One more evolution of these systems is the Intergenerational Business Model. It represents businesses where two or more generations of the same family are working at the business. The model was proposed by Weigel and is a system built of three subsystems: the older generation, the younger generation and the business [31].

Another family business model, based especially on conflict management, is the one developed by Belausteguigoitia called the Dynamic Organizational Model of the Family Business [32]. This model, based on the idea of a ship, seeks the balance of the organization between the three subsystems: business, ownership or property, and family. If one of the three subsystems have more weight than another, the imbalance can put the entire system at risk.

In the case of the model proposed by Carlock and Ward [33], six configurations of property are incorporated into the models seen earlier, and the individual element is considered. That is to say, it not only considers the family as a whole but also considers the needs of the private individual.

Bork propose a three-circle model where three subsystems exist: the family, the business and the individuals [34]. To achieve harmony, it is necessary for the three systems to be balanced and in the same stage, something that does not usually happen. Normally, the stages the business or the family are going through are not compatible with the stages the individuals that are experiencing.

\section{Objective}

The principal objective of this research is to develop a model that represents the small and medium-sized family business system, taking as a basis the existing theories on this type of business and in the field of management. To this end, a conceptual model was constructed based on a review of the literature, which is adapted to the reality of the small and medium-sized family business in the Mexico City Metropolitan Area and its later validation. The new model was built starting from the Three-Circle Model, but based on the reality of small and medium-sized family businesses in the aforementioned area of Mexico, which are rarely quoted on the stock exchange and in the majority of cases do not have external financial backers, which is the reason why the subsystem of ownership or property is not included. The Business, Family and Environment (BFE) Model is a variation on the Three-Circle Model [9], which is more focused on larger-sized companies. The variation of the proposed model is because the Mexican family-owned SME does not usually have shareholders outside of the family and, in many cases, does not have the levels of specialization in the operation and the quality of human capital that a larger-sized company has. In Figure 2 we can see the model graphically: 


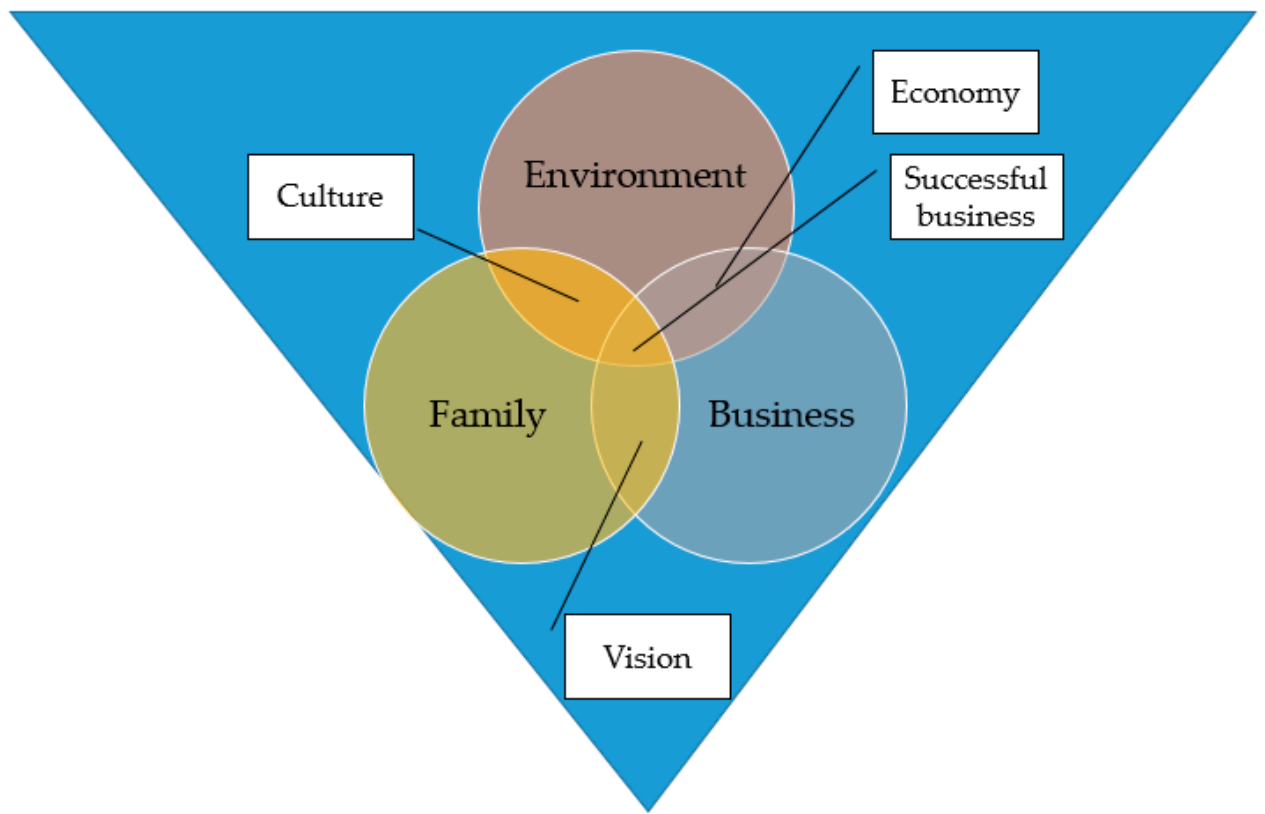

Figure 2. BFE (Business, Family and Environment) Model Source: Prepared by the authors.

The BFE Model is made up of three subsystems, which are defined in the following way:

The business subsystem of the BFE Model is defined as the subsystem representing an economic unit, in charge of the production of goods and services. are Cash flows are produced in this subsystem for the other two subsystems.

The family subsystem of the BFE Model is defined as the subsystem made up of the family members who may or may not be owners of the business, but who nevertheless can affect its operation. This includes relatives who work in the business and are not owners, relatives who do not work in the business and are owners, and relatives who work in the business and are owners. This subsystem can contribute with capital, people and knowledge to the other subsystems.

The environment subsystem of the BFE Model is defined as the subsystem formed by a group of external forces, which come from the environment, that affect decisions in the other two subsystems. This subsystem can contribute with people and knowledge to the other subsystems.

It is also important to emphasize the relationships created in each one of the intersections of this system:

- Economic Intersection: this is the intersection of the environment subsystem with the business subsystem. In this intersection, the business contributes economic flows to the economy, as it gives work to people outside of the family. The environment, in exchange, gives knowledge to the business through these people.

- Cultural Intersection: this is the intersection of the environment subsystem with the family subsystem. In this intersection, the family takes codes of conduct learned from the environment where it develops and contributes, in exchange, with people from the family, who continue preserving the culture from the society where it evolves.

- Vision Intersection: this is the intersection of the business subsystem with the family subsystem. In this intersection, the family gives their vision of life and the future to the business. The family also contributes with capital, knowledge and human capital. In exchange, the business provides economic flows to the family and possible work positions.

- Successful Business Intersection: this is the intersection of the three subsystems. In this intersection the three subsystems provide their resources to maximize the overall performance of the system.

Success of the total system depends on the three subsystems improving their performance and generating value by using the available resources, which may be money, people and knowledge. 
The hypotheses proposed in this work are presented below:

Hypotheses 1 (H1). In small and medium-sized family businesses in the Mexico City Metropolitan Area, decisions are made based on the problems in the family subsystem.

Hypotheses 2 (H2). In small and medium-sized family businesses in the Mexico City Metropolitan Area, decisions are made based on problems in the environment subsystem.

Hypotheses 3 (H3). In small and medium-sized family businesses in the Mexico City Metropolitan Area, decisions are not made based on problems in the ownership subsystem.

Hypotheses 4 (H4). In small and medium-sized family businesses in the Mexico City Metropolitan Area, decisions are made based on problems in the business subsystem.

Hypotheses 5 (H5). In small and medium-sized family businesses in the Mexico City Metropolitan Area, where tools are added to improve the business subsystem, better performance can be observed.

Hypotheses 6 (H6). In small and medium-sized family businesses in the Mexico City Metropolitan Area, where tools are added to improve the family subsystem, better performance can be observed.

Hypotheses 7 (H7). In small and medium-sized family businesses in the Mexico City Metropolitan Area, where tools are added to improve the environment subsystem, better performance can be observed.

Hypotheses 8 (H8). In small and medium-sized family businesses in the Mexico City Metropolitan Area, tools are not added to improve performance in the ownership subsystem.

Hypotheses 9 (H9). The small and medium-sized family businesses in the Mexico City Metropolitan Area live in an integrated system only because of the business, family and environment subsystems.

\section{Methodology and Discussion}

The present study attempts to answer the following questions: Do existing family business models respond to the reality of SMEs, when they consider the ownership subsystem as part of the system? and do family SMEs live in a system that is integrated with the three subsystems of the BFE Model (business, family and environment)?

To answer the research questions proposed, we used a mixed method of scientific research that includes qualitative and quantitative techniques in its design. The collection of information was carried out, through sampling by conglomerates and sub-sampling, calculating the ideal sample with $95 \%$ confidence. The Delphi method was used for selection of the sample experts in a non-probabilistic manner and, subsequently, for the data collection a Likert-Thurstone scale was applied (See Appendix A) for the ordinal and interval data. Afterwards, the results collected by the same Delphi Method were analyzed and, later, the data was subjected to statistical treatment in order to carry out a second confirmation. It was carried out through hypothesis testing and factorial analysis for the hypotheses $\mathrm{H} 1, \mathrm{H} 2, \mathrm{H} 3, \mathrm{H} 4, \mathrm{H} 5, \mathrm{H} 6, \mathrm{H} 7$ and H8; and test hypotheses and structural equations for hypothesis H9. Finally, the interpretation of results and elaboration of the conclusions of the same was carried out.

Information gathering from primary sources for this study was done by means of non-probability sampling for conglomerates, and for sub-sampling the Delphi Method was used. To do this, a Likert-Thurstone scale was applied for ordinal and interval data. Later, statistical treatment was given to the data for an additional confirmation of the results from the Delphi Method by means of hypothesis testing, factor analysis and structural equations. Information gathering from secondary sources was based on official documents, scientific magazines and official web pages. Likewise, books were consulted, especially those from classic authors.

The scale that was developed was applied to a total of 25 entrepreneurs, owners of family businesses in the Mexico City Metropolitan Area (See Table 1). 
Table 1. Characteristics of Participants.

\begin{tabular}{ccc}
\hline $\begin{array}{c}\text { Companies' Sales in Millions of } \\
\text { Mexican Pesos }\end{array}$ & Companies' Sales in Euros & Number of Participants \\
\hline Less than 5 million pesos & Less than 248,921 euros & 10 \\
\hline Les of less than 100 million pesos & Less than 4.97 million euros & 14 \\
\hline Less than 250 million pesos & Less than 12.44 million euros & 1 \\
\hline \multicolumn{2}{c}{ Total participants } \\
\hline
\end{tabular}

Of the 25 participating companies in the sample, 10 are from the industry sector, 13 are from the services sector and 2 are from the commerce sector. It is also important to note that only one of these enterprises is of micro size, while 14 are small enterprises and 10 are medium sized enterprises.

All participants are business owners of businesses which have been assisted by the consultancy department of the business accelerator at Anahuac University between 2007 and 2016, from a total population of 400 entrepreneurs. According to the Delphi Method, a maximum number of 30 participants is needed for this study, however, a calculation of the sample was made for confirmation, which produced an ideal number of 23 participants, fortunately, it was possible to obtain the participation of 25 entrepreneurs.

To calculate of the sample of the present study, the size of the probabilistic sample was calculated, considering that the variables are of the qualitative type and the population is finite with a value of 400, which is the total of the database of companies between those that were selected to the sample. This database was obtained from the Business Accelerator of Anahuac University.

The Likert-Thurstone scale used was built on a scale from 1 to 7 , in categories ranging from giving the option to the participant to manifest its null agreement, to the affirmation of the item or its total agreement, and prior to its application, we consulted with 2 thematic experts to make corrections to it. It is important to note that the values of $p=q=0.5$ are used to consider the maximum possible heterogeneity in the chosen sample, according to the margin of error. That is, $50 \%$ weighting is used to consider the maximum dispersion that can be presented in the answers to the questions, which are made to the elements of the sample. Likewise, the value of 1.96 is used, associated with the standard normal distribution, to indicate that there is a confidence interval of $95 \%$. This means that there is a $95 \%$ probability that the registered responses will be within the level that marks the error margin. If the population is composed of very diverse sample elements, that is, with very different characteristics, then a small margin of error will imply a sample size almost equal to the size of the population, since there are heterogeneous elements. Otherwise, if the population consists of extremely similar elements, a small margin of error will imply a small sample size. In both cases, the $95 \%$ confidence level indicates that in $95 \%$ of the cases the registered responses are located representatively within the population, according to the margin of error used.

The error margin was set to 0.20 to indicate the range in which a result may oscillate within the chosen sample. Given that the elements that make up the population of size 400 have very different characteristics, the margin of error of 0.20 implies that the registered responses can deviate up to $20 \%$, but that allows a small sample to cover as much variation as possible within the sample suggested by the Delphi method (maximum 30 elements). In this case, the margin of error was chosen to gather as much variation as possible in a small sample and that was according to the suggestion established by the Delphi method. That is, both the qualitative and quantitative parts were reconciled with the $20 \%$ level.

No payment or incentive was made to the participants, and because of privacy agreements it is not possible to reveal their personal information. 


\section{Results}

The present work considers four variables that are defined below:

- $\quad$ Ownership Subsystem: The ownership subsystem is defined as the subsystem formed by those owners of the company who are not part of the family (in consanguine or political form).

- Environment Subsystem: The environment subsystem surrounding the EFEV Model is defined as the subsystem formed by a group of external forces from the environment that affect the actions and decisions of the other two subsystems. This subsystem can provide people and knowledge to the other subsystems.

- Business Subsystem: The business subsystem of the EFEV Model, is defined as the subsystem representing an economic unit. In charge of the production of goods and services, in this subsystem cash flows are generated for the other two subsystems.

- $\quad$ Family Subsystem: The family subsystem of the EFEV Model, is defined as the subsystem formed by the members of the family, whether or not they are owners of the company, but which, however, can affect the operation of the same, includes family members who work within the company and are not owners, family members who do not work in the company and are owners and family members who work in the company and are owners. This subsystem can provide capital to the other subsystems, people and knowledge.

\subsection{Qualitative Results Obtained from the Likert-Thurstone Scale}

Presented below are consolidated results from some of the questions (the entirety of the 22 items appear in Appendix A) from the scale applied to the 25 participants:

According to Figure 3, 40\% of the participants, 10 of them, disagree with the statement that their business is in a system made up of the business, family and external shareholders. Of the remaining participants, only seven consider themselves completely in agreement, in agreement or partly in agreement with this statement.

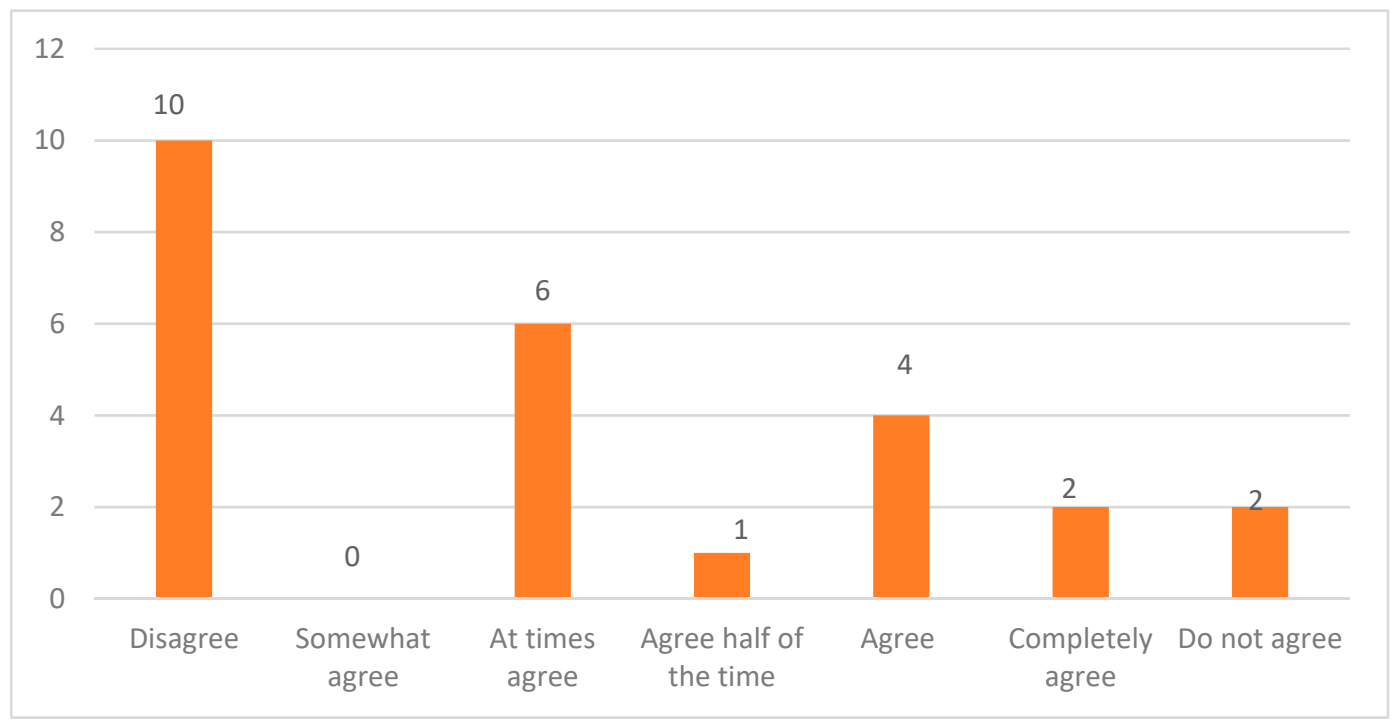

Figure 3. Question chosen from the applied scale. My family business is in a system made up of three elements: business, family and external shareholders. I do not feel we are affected by the environment or the community. Source: Prepared by the authors. 
According to Figure 4, only six of the 25 participants completely disagree with the statement that their company is in a system made up of three elements and do not have external shareholders. In fact, 16 of the 25 participants (64\%) indicate that they agree or completely in agreement with this statement.

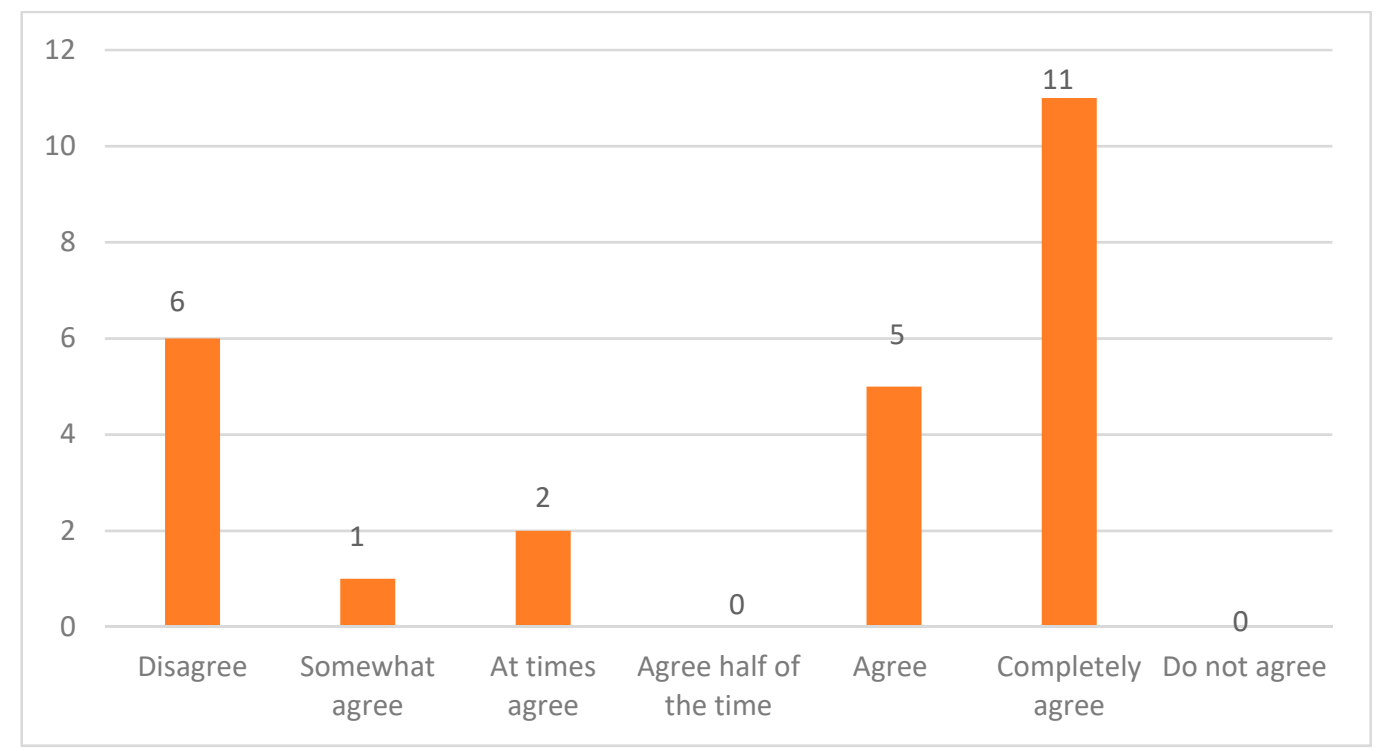

Figure 4. Question chosen from the applied scale. My family business is in a system made up of three elements: business, family and environment (or community); we do not have external shareholders. Source: Prepared by the authors.

Figure 5 shows that in eight of the 25 cases (32\%), participants indicate that the relevance of the impact on the business from incorporating tools to improve their relationship with the environment is high. Eight percent (two of 25 participants) even consider the impact to be very high. Sixteen percent (four of 25 participants) consider that the impact has a medium level, and only six participants consider that the impact from taking these actions is low, very low or null. It is important to point out that five of the 25 participants (20\%) indicate that they have never incorporated these types of tools.

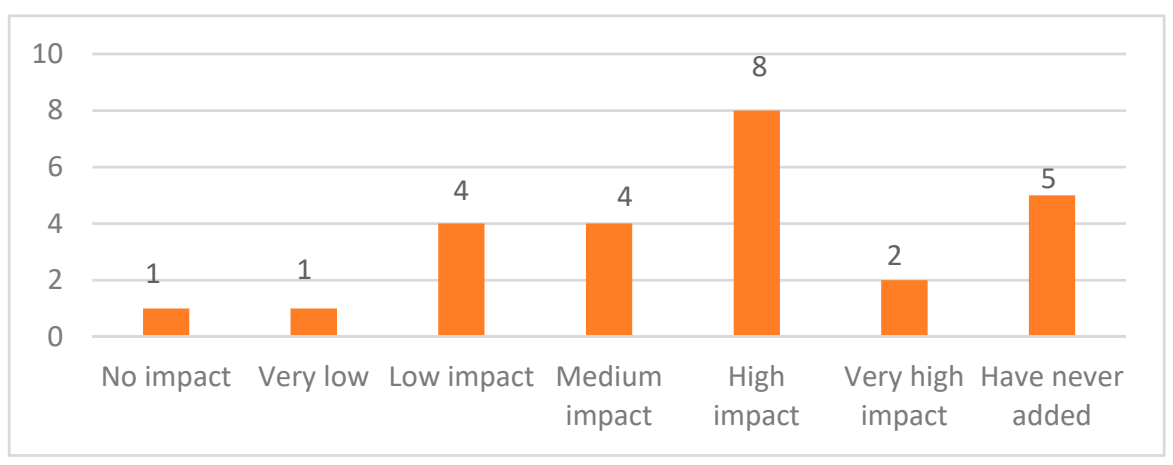

Figure 5. Question chosen from the applied scale. The level of impact on your company from incorporating tools to improve relationships with your environment is. Source: Prepared by the authors.

Figure 6 shows that in 17 of the 25 cases (68\%) the relevance on business performance from new associates who are not family members joining and/or leaving the company is null owing to the fact that, as can be seen in the graphic, the majority of the businesses surveyed do not have shareholders who do not form part of the family. 


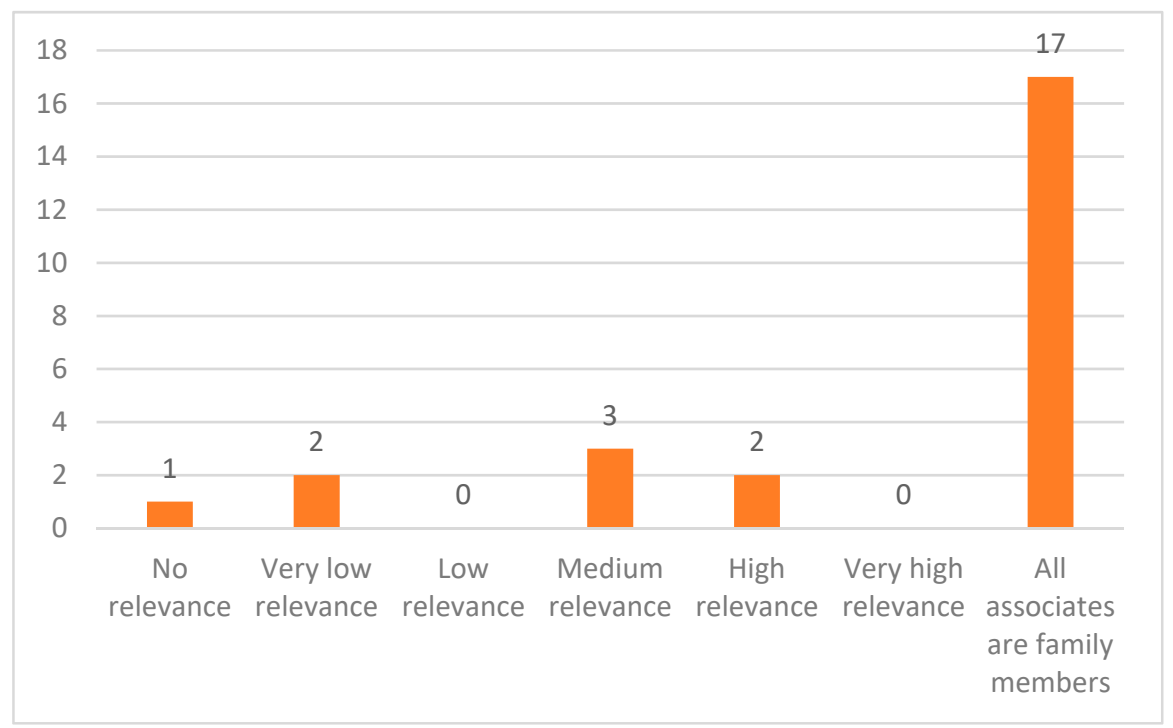

Figure 6. Question chosen from the applied scale. The relevance on business performance from new associates who are not family members joining or leaving the company. Source: Prepared by the authors.

\subsection{Quantitative Results from the Data Analysis}

With respect to the results after data processing, the following results were obtained:

From the results obtained with the scale, a numerical value was assigned to each one of the participants' answers and the information was processed in a data processing software.

The averages, standard deviation and maximum and minimum values are presented in Table 2. Considering that the scale was constructed from 1 to 7 , where 1 and 7 represent a zero-rated level of performance, impact, pertinence or relevance depending on how the item is applied, and from number 2 to 6 represents some level of performance, impact, pertinence or relevance depending on how the item is applied; it can be seen that the highest standard deviations belong to Items 3, 5, 8, 21 and 22; that is to say, these are the items in which responses from the participants show greater dispersion. In Items 3 and 8, the relevance of the environment for shareholders is asked and, in the opposite sense, that of the shareholders for the environment. This supposes a low relationship between the variables of environment and ownership. Finally, in Items 21 and 22, the feasibility that the BFE Model represents the reality of small and medium-sized businesses in the Mexico City Metropolitan Area is questioned. In the case of Item 21, as the average is 4.1 and the standard deviation is 2.12 , it can be seen that the majority of participants indicate they agree with the statement, from a little to completely, that their family business contains a system made up of three subsystems: business, family and environment. In Item 22, in contrast, the participants were asked if their business contains a system made up of these subsystems: business, family and ownership. In this sense, half of the participants express agreement only half of the time, and in accordance with the standard deviation, the responses vary from those who disagree with the statement to those who agree.

Hypothesis testing was done with a confidence level of $95 \%$ and a value of $50 \%$ for the null hypothesis, which is defined as $\mathrm{H} 0=0.5$ for all $\mathrm{H} 1$ to $\mathrm{H} 9$ hypotheses. The alternative hypotheses $\mathrm{H} 1$ are defined as $\mathrm{H} 1: \mathrm{p}>0.5, \mathrm{H} 1: \mathrm{p}<0.5$ and $\mathrm{H} 1: \mathrm{p} \neq 0.5$. Hypotheses $\mathrm{H} 1$ to $\mathrm{H} 9$ were accepted as they met the criteria that $\mathrm{HO}$ is rejected if the test statistic falls within the critical region, that is to say, if the probability is low that the test statistic falls within the critical region. The criteria is met for more than $95 \%$ of the population, except for H8, where it is met by $91.9 \%$ of the population. In Table 3, results of the hypothesis testing are shown: 
Table 2. Average, Standard Deviation, Minimum and Maximum.

\begin{tabular}{|c|c|c|c|c|c|}
\hline Item & Observations & Average & Standard Deviation & Minimum & Maximum \\
\hline Item 1 & 25 & 5.8 & 1.9079 & 1 & 7 \\
\hline Item 2 & 25 & 5.9 & 1.7776 & 1 & 7 \\
\hline Item 3 & 25 & 5.4 & 2.2927 & 1 & 7 \\
\hline Item 4 & 25 & 6.1 & 1.4524 & 2 & 7 \\
\hline Item 5 & 25 & 5.5 & 2.1209 & 1 & 7 \\
\hline Item 6 & 25 & 4.4 & 1.7300 & 1 & 7 \\
\hline Item 7 & 25 & 4.5 & 1.6260 & 1 & 7 \\
\hline Item 8 & 25 & 4.2 & 2.2111 & 1 & 7 \\
\hline Item 9 & 25 & 4.7 & 1.6462 & 1 & 7 \\
\hline Item 10 & 25 & 4.6 & 1.7559 & 1 & 7 \\
\hline Item 11 & 25 & 5.5 & 1.0847 & 1 & 6 \\
\hline Item 12 & 25 & 4.0 & 1.6452 & 1 & 7 \\
\hline Item 13 & 25 & 6.3 & 0.9798 & 4 & 7 \\
\hline Item 14 & 25 & 5.2 & 0.9695 & 3 & 7 \\
\hline Item15 & 25 & 5.6 & 0.7681 & 3 & 6 \\
\hline Item 16 & 25 & 4.9 & 1.2557 & 1 & 6 \\
\hline Item 17 & 25 & 3.6 & 1.6330 & 1 & 7 \\
\hline Item 18 & 25 & 5.6 & 1.7032 & 1 & 7 \\
\hline Item 19 & 25 & 5.0 & 1.5406 & 2 & 7 \\
\hline Item 20 & 25 & 4.6 & 1.3819 & 2 & 7 \\
\hline Item 21 & 25 & 4.2 & 2.1213 & 1 & 6 \\
\hline Item 22 & 25 & 3.1 & 2.1079 & 1 & 7 \\
\hline
\end{tabular}

Table 3. Results of Hypothesis Testing.

\begin{tabular}{ccc}
\hline Hypothesis & Test Statistic (z) & $p$-Value \\
\hline H1 & 4.2 & 0.0000 \\
\hline H2 & 2.6 & 0.0047 \\
\hline H3 & 1.8 & 0.0359 \\
\hline H4 & 5 & 0.0000 \\
\hline H5 & 4.6 & 0.0000 \\
\hline H6 & 2.2 & 0.0139 \\
\hline H7 & 2.6 & 0.0047 \\
\hline H8 & 1.4 & 0.0808 \\
\hline H9 item 21 & 2.6 & 0.0047 \\
\hline H9 item 22 & 2.7 & 0.0047 \\
\hline
\end{tabular}

Source: Prepared by the authors.

With respect to factor analysis of the data, analysis of Items 5, 10, 15 and 20 can be seen in Table 4, corresponding to the dimension related to decision-making. It can be observed that the subsystem having the least weight is that of ownership, represented in Item 5 with a weight of 0.3646. 
Table 4. Results of Factor Analysis of the Data for Hypotheses H1, H2, H3 and H4.

\begin{tabular}{ccc}
\hline Item & Factor $\mathbf{1}$ & Factor 2 \\
\hline 5 & 0.3646 & 0.2862 \\
\hline 10 & 0.3867 & 0.2721 \\
\hline 15 & 0.4733 & -0.2259 \\
\hline 20 & 0.4619 & -0.2222 \\
\hline \multicolumn{2}{l}{ Source: Prepared by the authors }
\end{tabular}

With respect to the factor analysis results for hypotheses H5, H6, H7 and H8, in Table 5 it can be seen that the subsystem having the least weight in relation to the performance dimension is the ownership subsystem, represented in Item 4 with a weight of -0.3041 .

Table 5. Results of Factor Analysis of the Data for Hypotheses H5, H6, H7 and H8.

\begin{tabular}{ccc}
\hline Item & Factor $\mathbf{1}$ & Factor 2 \\
\hline 14 & 0.5026 & 0.01 \\
\hline 19 & 0.2187 & 0.2409 \\
\hline 9 & 0.1578 & 0.239 \\
\hline 4 & -0.3041 & 0.3138 \\
\hline
\end{tabular}

Source: Prepared by the authors.

With respect to analysis of structural equations (developed in Appendix B), it can be seen in Table 6 that the subsystem with the least weight is the ownership subsystem, with a value of 0.5056 in the covariance calculation. Thus, it can be inferred that as the ownership subsystem has less weight than the business, environment and family subsystems, it is the least relevant:

Table 6. Results of Structural Equations.

\begin{tabular}{lllll}
\hline Factors & Variance & Standard Error & & $p$-Value \\
\hline Environment Subsystem & 4.6018 & 1.3553 & & 0.000 \\
Business Subsystem & 1.3561 & 0.3767 & & 0.000 \\
Family Subsystem & 0.8817 & 0.3814 & 0.010 \\
Ownership Subsystem & 4.3497 & 0.7538 & & 0.000 \\
\hline Factors & Covariance & Standard Error & Correlation & $p$-Value \\
\hline Environment Subsystem & & & & \\
Business Subsystem & 1.348 & 0.2982 & 0.5396 & 0.000 \\
Family Subsystem & 1.6912 & 0.3608 & 0.8396 & 0.000 \\
Ownership Subsystem & 1.6246 & 0.557 & 0.3631 & 0.000 \\
\hline Business Subsystem & & & & \\
Family Subsystem & 0.7166 & 0.2824 & 0.6553 & 0.000 \\
Ownership Subsystem & 1.2279 & 0.2921 & 0.5056 & 0.000 \\
\hline Family Subsystem & & & & \\
Ownership Subsystem & 0.7394 & 0.348 & 0.3776 & 0.000 \\
\hline
\end{tabular}

Source: Prepared by the authors.

\section{Conclusions}

The purpose of this research was to develop and test a conceptual model that represents a system that represents small and medium-sized family businesses, in the Mexico City Metropolitan Area, based on existing management theories about these kinds of businesses. The model proposed is based on the well-known "Three-Circle Model" proposed by Tagiuri and Davis, having three subsystems: 
business, family and ownership. In the proposed adaptation of the model, in contrast to previously proposed modified models [9,31-34], the ownership or ownership subsystem was replaced by the environment subsystem.

There are several future lines of research: a future line of research is to expand the number of companies to which the study was applied, another option is to do it only with companies in a specific sector or in other regions of Mexico. Another important line of research is to apply the study in companies from other regions of Latin America or the world. Research methods, especially in family business, are studied and examines the progression and development of methodologies, sample sizes and related methodological issues, as well as theories and topics studied in family business research [35]. Another future line is related with the internationalization of family businesses. From a managerial perspective, family-business managers ought to be aware of their strengths concerning internationalization and take advantage of them. Specific advantages in the context of internationalization include a long-term view, a high level of trust, and the possibility to make quick decisions [36].

In respect to the feasibility that the BFE Model represents the reality of small and medium-sized businesses in the Mexico City Metropolitan Area, it was observed that the majority of participants indicated the scale applied by the Delphi Method in their responses: that their family business is contains a system made up of three subsystems: business, family and environment; that in the majority of the cases the decision-making is not done based on priorities from external shareholders; and finally, that tools to improve performance of the ownership or property subsystem are not incorporated.

With respect to validation of the hypotheses by means of hypothesis testing, those named $\mathrm{H} 1, \mathrm{H} 2$, $\mathrm{H} 3, \mathrm{H} 4, \mathrm{H} 5, \mathrm{H} 6, \mathrm{H} 7$ and $\mathrm{H} 8$ were accepted as they met the criteria that $\mathrm{H} 0$ is accepted if the test statistic does not fall within the critical region, that is to say, if the probability is low that the test statistic falls within the critical region.

Regarding to the decision-making dimension considered in hypotheses $\mathrm{H1}, \mathrm{H} 2, \mathrm{H} 3$ and $\mathrm{H} 4$, it was validated that in family businesses the impact on the environment subsystem, family subsystem and, of course, the business subsystem are taken into consideration when decisions are made, but not the ownership or property subsystems. For the performance dimension, it was found that in family businesses that incorporate tools to improve performance, impacts are shown on the environment, family and business subsystems, which validates hypotheses $\mathrm{H} 5, \mathrm{H} 6, \mathrm{H} 7$ and $\mathrm{H} 8$. In contrast, in the majority of cases tools to improve the ownership subsystem are not incorporated, which suggests that it does not have high relevance within the system.

Regarding to results from the factor analysis, when making an analysis of Items 5, 10, 15 and 20 , corresponding to the decision-making dimension, it was found that the subsystem with the least weight in the decision-making dimension is the ownership subsystem, represented in Item 5 with a weight of 0.3646 .

With respect to results from the factor analysis for hypotheses H5, H6, H7 and H8, it can be seen that the subsystem showing the least weight in the performance dimension is the ownership subsystem, represented in Item 4 with a weight of -0.3041 .

Finally, after resolving the structural equations to validate hypothesis $\mathrm{H} 9$, it was found that the subsystem with the least weight in the correlation calculation is the ownership subsystem, with weights of $0.3776,0.3631$ and 0.5056 . It is inferred, then, that as the ownership subsystem has less weight, it is the least relevant subsystem. To provide additional confirmation, a hypothesis test was also done for Items 21 and 22. It was validated for Items 21 and 22 that, having a $p$-value of 0.0047 for both tests, it could thus be validated that the majority of participants think their system is composed of the three elements in the BFE system: business, family and environment.

Based on the responses of the participants, the results suggest that there is a low relationship between the variables or subsystems environment and ownership, although this was not the purpose of the study, it opens a possibility of further research by analyzing the interaction of these two subsystems in the SMEs of the Mexico. Another way to interpret it, would be to look as a future line of research 
which is the relationship between shareholders who are not part of the family and the environment, how they make their decisions and if their performance has to be related to one another. This finding goes back to the two positions that exist about the behavior of family businesses in the face of Corporate Social Responsibility.

The first, which holds that preference is given to the family over the company and the second that maintains that the family business can be associated with community support, concern for quality and reputation, respect for values and traditions, among others family values transported from the family to the company [26]. This topic opens a window of research on this relationship. Another window of investigation is to deepen into the reasons why in item 14, some participants indicated not to incorporate tools to improve the management of the company. It can also be noted that in item 19, some participants comment not having incorporated tools to improve family relationships, that is, the family government has not been professionalized; this point is relevant to analyze in the future to consider the effect on the survival of the family business of not incorporating these kinds of tools.

An important limitation of this research is that it could expand the number of entrepreneurs who participated in it, in addition to that it could be carried out in other geographical areas of Mexico or in other Latin American countries to analyze the differences in the results.

We can conclude that the BFE Model adapts to the reality of the small and medium-sized family businesses in the Valle de México Metropolitan Area. The ownership subsystem has less relevance, given that few businesses have external shareholders, although they are indeed influenced by the environment surrounding them.

Author Contributions: "visualization, writing-review and editing O.d.l.C.V.; conceptualization, methodology, investigation, writing-original draft preparation and formal analysis V.I.L.C.; resources, data curation and software L.M.M.; writing - review and editing, methodology, investigation, supervision, resources, validation, project administration F.T.B.".

Funding: This research received no external funding.

Conflicts of Interest: The authors declare no conflict of interest.

\section{Appendix A}

Likert-Thurstone Scale Items Constructed for the Study (1-7)

1. The relevance it has on performance at your business when new business associates, not related to the family, join or leave the business, is:

2. The relevance it has on relationships in your family when new business associates, not related to the family, join or leave the business, is:

3. The relevance it has on the environment or your community when new business associates, not related to the family, join or leave the business, is:

4. The level of impact on your company, when tools are incorporated to improve your relationships with shareholders, who are not blood relatives or in-laws (no family relationship):

5. Decision-making in your company is done based on the external's shareholders priorities and trying to meet their expectations and increase their profits.

6. The relevance that changes in the environment or in your community have on the performance of your company is:

7. The relevance that changes in the environment or in your community have on the relationships with your family is:

8. The relevance that changes in the environment or in your community have on performance with external shareholders:

9. The level of impact on your company of incorporating tools to improve relationships with the environment is:

10. Decision-making in your company is done based on changes in the environment, interested parties and the impact that these changes create in us or we create on them: 
11. The relevance that the existence or disappearance of the business has on your family:

12. The relevance that the existence or disappearance of the business has on your environment or your community:

13. The relevance that the existence or disappearance of the business has for your external shareholders:

14. The level of impact of incorporating tools to improve management at your company, to improve performance, is:

15. Decision-making in your business is done based on improving management of the business and increasing its profitability:

16. The relevance your family have on the performance and existence of the business is:

17. The relevance your family have to changes in the environment or on your community is:

18. The relevance your family has in the relationship with external shareholders is:

19. The level of impact that implies incorporating tools to improve family relationships is:

20. Decision-making in your business is done based on the economic as well as emotional well-being of the family:

21. My family business has a system made up of three elements: business, family and environment (or community), we do not have external shareholders.

22. My family business has a system made up of three elements: business, family and external shareholders; I do not think we are affected by the environment or the community.

\section{Appendix B}

Described below are the results from resolving the structural equations for hypothesis H9: "Small and medium-sized Mexican family businesses live in a system made up of only the business, family and environment subsystems."

In this exercise it was sought to find the correlation between the latent factors that describe the ownership (X), environment (Y), business (Z) and family (W) subsystems by means of the information compiled in the different items from the survey carried out.

The corresponding equations are:

$$
\begin{gathered}
p_{1}=\alpha_{1}+\beta_{1} X+\varepsilon_{1} \\
p_{2}=\alpha_{2}+\beta_{2} X+\varepsilon_{2} \\
p_{3}=\alpha_{3}+\beta_{3} X+\varepsilon_{3} \\
p_{6}=\alpha_{6}+\beta_{6} Y+\varepsilon_{6} \\
p_{7}=\alpha_{7}+\beta_{7} Y+\varepsilon_{7} \\
p_{8}=\alpha_{8}+\beta_{8} Y+\varepsilon_{8} \\
p_{11}=\alpha_{11}+\beta_{11} Z+\varepsilon_{11} \\
p_{12}=\alpha_{12}+\beta_{12} Z+\varepsilon_{12} \\
p_{13}=\alpha_{13}+\beta_{13} Z+\varepsilon_{13} \\
p_{16}=\alpha_{16}+\beta_{16} W+\varepsilon_{16} \\
p_{17}=\alpha_{17}+\beta_{17} W+\varepsilon_{17} \\
p_{18}=\alpha_{18}+\beta_{18} W+\varepsilon_{18}
\end{gathered}
$$

where the coefficients $\alpha_{\text {st }}$ are the intercepts of each equation and $\beta_{\text {st }}$ the loadings that associate each factor with each item; $p_{j}$ identifies question number $j$ on the survey, $j=1,2, \ldots, 22$ and the random 
terms $\varepsilon_{\text {st }}$ that correspond to each latent factor that describes the corresponding subsystem. It is also possible to express the equations in the following manner:

$$
\begin{gathered}
p_{1}=X+\varepsilon_{1} \\
p_{2}=1.108203 X+\varepsilon \\
p_{3}=1.039793 X+\varepsilon_{3} \\
p_{6}=Y+\varepsilon_{6} \\
p_{7}=1.01506 Y+\varepsilon_{7} \\
p_{8}=0.9665439 Y+\varepsilon_{8} \\
p_{11}=Z+\varepsilon_{11} \\
p_{12}=1.229963 Z+\varepsilon_{12} \\
p_{13}=1.995698 Z+\varepsilon_{13} \\
p_{16}=W+\varepsilon_{16} \\
p_{17}=1.307679 W+\varepsilon_{17} \\
p_{18}=2.129879 W+\varepsilon_{18}
\end{gathered}
$$

\section{References}

1. Benavides, C.; Guzmán, V.; Quintana, C. Evolución de la literatura sobre empresa familiar como disciplina científica. In Cuadernos de Economía y Dirección de la Empresa; Escuela Técnico Superior de Ingenieros Industriales: Málaga, Spain, 2011; pp. 78-90.

2. Poza, E. Family Business; Cengage Learning US: Boston, MA, USA, 2014.

3. Angulo, K. La Empresa Familiar una temática en desarrollo. Revisión Literaria. In Oikos Polis-Revista Latinoamericana de Ciencias Económicas y Sociales; Universidad Autónoma Gabriel Rene Moreno: Santa Cruz, Bolivia, 2016; pp. 175-198.

4. Benavides, C.; Guzmán, V.; Quintana, C. Trends in family Business Research. Small Bus. Econ. 2013, 40, 41-57. [CrossRef]

5. Vallejo Martos, M. Cuando definir es una necesidad. Una propuesta integradora y operativa del concepto de empresa familiar. In Investigaciones Europeas de Dirección y Economía de la Empresa; Universidad de Jaén: Jaén, Spain, 2005; pp. 151-171.

6. Gersick, K.; Davis, J.; Hampton, M.; Lansberg, I. Generation to Generation; Harvard Business School Press: Boston, MA, USA, 1997.

7. Tápies, J. Empresa familiar: un enfoque multidisciplinar. In Universia Business Review; Grupo Recoletos Comunicación: Madrid, Spain, 2011; pp. 12-25.

8. Instituto Nacional de Estadística, Geografía e Informática. Estadistics. Mexico City (Mexico). 2014. Available online: http://www.inegi.gob.mx (accessed on 15 May 2019).

9. Tagiuri, R.; Davis, J. Bivalent Attributes of Family Business. In Family Business Review; Elsevier: London, UK, 1996; pp. 199-208.

10. McFarlin, D. Does Family matter to corporate performance? In Academy of Management Review; Academy of Management: Nueva York, NY, USA, 2008; pp. 100-101.

11. Charbel, S.; Elie, B.; George, S. Impact of family involvement in ownership management and direction on financial performance of the Lebanese firms. Int. Strateg. Manag. Rev. 2013, 54, 30-41. [CrossRef]

12. Schmidts, T.; Sheperd, D. Social identity theory and family business: A contribution to understanding family business dinamics. Small Enterp. Res. 2013, 20, 76-86. [CrossRef]

13. Cacho, P.; Grande, F.; Pedrosa, C. El reto de la dirección de recursos humanos para las empresas familiares: estado de la cuestión. Negotium 2012, 23, 139-162. 
14. Longenecker, J.; Petty, J.; Palich, L.; Hoy, F. Administración de Pequeñas Empresas; Cengage Learning Editores: México, México, 2010.

15. Le Breton-Miller, I.; Miller, D. Socioemotional Wealth across the family firm life cycle: A commentary on Family Business survival and the role of bards. In Entrepreneurship: Theory E Practice; Wiley-Blackwell: Nueva York, NY, USA, 2013; pp. 1391-1397.

16. Kets de Vries, M. The Dynamics of Family Controlled Firms: The Good and the Bad News. In Organizational Dynamics; Elsevier: Amsterdam, The Netherlands, 1993; pp. 59-71.

17. Jang, J.; Danes, S. Role interference in Family Business. Entrep. Res. J. 2012, 3, 367-390.

18. Chiner, A. La necesidad de un buen gobierno de la familia en las empresas familiares. In Universia Business Review; Grupo Recoletos: Madrid, Spain, 2011; pp. 102-110.

19. Trevinyo-Rodríguez. Empresas Familiares: Visión Latinoamericana; Pearson: México, México, 2010.

20. Leach, P. La empresa Familiar; Ediciones Granica: Buenos Aires, Argentina, 2010.

21. Cheng, Q. Family Firm Research-A review. China J. Account. Res. 2014, 7, 149-163. [CrossRef]

22. Diaz, H.; Fuentes, E. La comunicación en la empresa familiar, principal elemento en la preservación de la armonía familiar. Rev. Int. Admin. Finanz. 2013, 6, 95-114.

23. Ginebra, J. Las empresas Familiares: Su dirección y Continuidad; Editorial Panorama: México, México, 1997.

24. Monteferrante, P. Entre la Familia y el negocio: El desafío de gobernar una empresa Familiar; Debates IESA; Instituto de Estudios Superiores de Administración: Caracas, Venezuela, 2012; pp. 57-62.

25. González, M.; Guzmán, A.; Pombo, C.; Trujillo, M. Empresas familiares: revisión de la literatura desde una perspectiva de agencia. In Cuadernos De Administración; Universidad Javeriana: Bogotá, Colombia, 2010; pp. 11-33.

26. De Massis, A.; Frattini, F.; Lichtenthaler, U. Research on Technological Innovation in Family Firms: Present and Future Directions. Fam. Bus. Rev. 2016, 1-12. [CrossRef]

27. Szczepkowska, M. Social Responsability of Family Businesses: The case of Polish Large Entities. J. Eur. Union Res. Bus. 2019, 2019, 2-12.

28. Mahto, R.V.; Davis, P.S.; Pearce, J.A.; Robinson, R.B. Satisfaction with firm performance in Family Business. Entrep. Theory Pract. 2010, 34, 985-1001. [CrossRef]

29. Centro de Excelencia en Gobierno Corporativo. Sucesión en la empresa Familiar; LID Editorial Mexicana: México, México, 2010.

30. Molina, P.; Botero, S.; Montoya, J. Empresas de Familia: conceptos y modelos para su análisis. In Pensamiento y Gestión; Universidad del Norte: Medellín, Colombia, 2016; pp. 116-149.

31. Weigel, J. A Model of Interaction in the Intergenerational Family Business. Master's Thesis, University of Nevada, Reno, NV, USA, 1992.

32. Belausteguigoitia, I. Empresas Familiares: su Dinámica, Equilibrio y Consolidación; McGraw-Hill: México, México, 2010.

33. Carlock, S.; Ward, L. La planificación Estratégica de la Familia Empresaria; Deusto: Barcelona, Spain, 2001.

34. Bork, D.; Jaffe, D.; Lane, S. Cómo trabajar con la Empresa Familiar; Ediciones Juan Granica: Barcelona, Spain, 1997.

35. Wilson, S.R.; Whitmoyer, J.G.; Pieper, T.M.; Astrachan, J.H.; Hair, J.F., Jr.; Sarstedt, M. Method trends and method needs: Examining methods needed for accelerating the field. J. Fam. Bus. Strategy 2014, 5, 4-14. [CrossRef]

36. Kontinen, T.; Ojala, A. The internationalization of family businesses: A review of extant research. J. Fam. Bus. Strategy 2010, 1, 97-107. [CrossRef]

(C) 2019 by the authors. Licensee MDPI, Basel, Switzerland. This article is an open access article distributed under the terms and conditions of the Creative Commons Attribution (CC BY) license (http://creativecommons.org/licenses/by/4.0/). 